\title{
Biodegradable CpG DNA hydrogels for sustained delivery of doxorubicin and immunostimulatory signals in tumor-bearing mice.
}

\section{AUTHOR(S):}

Nishikawa, Makiya; Mizuno, Yumiko; Mohri, Kohta; Matsuoka, Nao; Rattanakiat, Sakulrat; Takahashi, Yuki; Funabashi, Hisakage; Luo, Dan; Takakura, Yoshinobu

\section{CITATION:}

Nishikawa, Makiya ... [et al]. Biodegradable CpG DNA hydrogels for sustained delivery of doxorubicin and immunostimulatory signals in tumor-bearing mice.. Biomaterials 2010

\section{ISSUE DATE:}

2010-10-05

\section{URL:}

http://hdl.handle.net/2433/131741

\section{RIGHT:}

(c) 2010 Published by Elsevier Ltd.; この論文は出版社版でありません。 引用の際には出版社版をご確認ご利用ください。; This is not the published version. Please cite only the published version. 


\title{
Biodegradable CpG DNA hydrogels for sustained delivery of doxorubicin and immunostimulatory signals in tumor-bearing mice
}

\author{
Makiya Nishikawa ${ }^{*}$,a, Yumiko Mizuno ${ }^{\text {a }}$, Kohta Mohri ${ }^{\text {a }}$, Nao Matsuoka ${ }^{\text {a }}$, Sakulrat Rattanakiat ${ }^{\text {a }}$, Yuki \\ Takahashi $^{\mathrm{a}}$, Hisakage Funabashi ${ }^{\mathrm{b}}$, Dan Luo ${ }^{\mathrm{b}}$ and Yoshinobu Takakura ${ }^{\mathrm{a}}$
}

\begin{abstract}
${ }^{a}$ Department of Biopharmaceutics and Drug Metabolism, Graduate School of Pharmaceutical Sciences, Kyoto University, Sakyo-ku, Kyoto 606-8501, Japan; ${ }^{b}$ Department of Biological and Environmental Engineering, Cornell University, Ithaca, New York 14853-5701, USA
\end{abstract}

\begin{abstract}
Immunostimulatory CpG DNA was self-assembled to form DNA hydrogels for use as a sustained delivery system for both intercalated doxorubicin (DXR) and immunostimulatory CpG motifs for cancer treatment. X-shaped DNA (X-DNA) was designed as a building unit, and underwent ligation to form DNA hydrogels. Two types of X-DNA were constructed using four oligodeoxynucleotides each, one containing six potent $\mathrm{CpG}$ motifs (CpG X-DNA) and the other with none (CpG-free X-DNA). CpG X-DNA was more effective than its components or the CpG-free counterpart in terms of the production of tumor necrosis factor- $\alpha$ from murine macrophage-like RAW264.7 cells, as well as maturation of the murine dendritic DC2.4 cells. The cytotoxic effects of X-DNA, DXR and their complexes were examined in a co-culture system of colon26/Luc cells, a murine adenocarcinoma clone stably expressing firefly luciferase, and RAW264.7 cells. DXR/CpG X-DNA showed the highest ability to inhibit the proliferation of colon26/Luc cells. DXR was slowly released from CpG DNA hydrogels. Injections of DXR/CpG DNA hydrogels into a subcutaneous colon26 tumor effectively inhibited tumor growth. These results show that CpG DNA hydrogels are an effective sustained system for delivery of immunostimulatory signals to TLR9-positive immune cells and DXR to cancer cells.
\end{abstract}

\section{Introduction}

The use of immunostimulatory agents has a long history in cancer chemo/immunotherapy [1]. This is at least partly because the immune system, the most powerful system for preventing cancerous cells from propagating, is greatly impaired in cancer patients and reactivation of the system is believed to be effective in killing cancer cells. A variety of immunostimulatory agents have been developed and used as adjuvants, and their effects have been shown not only in animal models but also in cancer patients [2-4]. Unmethylated cytosine-phosphate-guanine (CpG) dinucleotide, or $\mathrm{CpG}$ motif, is a well-known pathogen-associated molecular pattern that is a danger signal for the invasion of pathogens, like bacteria [5]. The mammalian immune system recognizes it using Toll-like receptor 9 (TLR9) and releases a variety of proinflammatory cytokines, including tumor necrosis factor (TNF)- $\alpha$ and interleukin (IL)-12 [6-8], leading to the stimulation of both innate and adaptive immune responses. These responses have been shown to be effective in inhibiting tumor growth and metastasis in tumor-bearing animal models [9,10].

DNA has a variety of advantages as a drug delivery system. For instance, DNA is highly soluble in aqueous solution, it can be chemically synthesized on a large scale, it is highly stable in powder form or in solution if contains no degrading enzymes, it is also biodegradable, and capable of binding low-molecular-weight compounds, including anticancer agents. In a previous study, we demonstrated that doxorubicin (DXR) can be intercalated into CpG motif-containing plasmid DNA and delivered to metastatic colonies of colon carcinoma cells in mouse liver [11]. Thus, DNA is a promising polymer that can be used as a delivery system for immunostimulatory signals and anticancer agents, a combination that would be highly effective for tumor chemo/immunotherapy. Plasmid DNA has some advantages for this application, since it is simple to prepare and has an abundance of CpG motifs. However, a major drawback is the fast release of DXR from plasmid DNA. Obtaining a sustained release rate of DXR from immunostimulatory CpG DNA would greatly increase the potency of such DXR complexed CpG DNA preparations in cancer therapy.

Recent great advances in the technology of developing DNA-based nanostructures have made it possible to design a variety of forms of DNA nanoassemblies [12,13]. We have shown that the immunostimulatory activity of CpG DNA is increased by using it to build highly branched structures such as Y-shaped DNA [14] and dendrimer-like DNA [15]. Further ligation of structured DNA units, such as X-shaped DNA (X-DNA), results in DNA hydrogels [16]. Because hydrogels are a class of drug delivery systems that can control the release rate of incorporated drugs either by erosion or diffusion through polymeric matrix [17], DNA hydrogels consisting of CpG DNA are an ideal system for sustained release of both the immunostimulatory signal and anticancer agents.

In the present study, we designed a new highly immunostimulatory DNA unit by incorporating six highly potent CpG motifs into X-DNA, and prepared CpG DNA hydrogels by ligation using a DNA ligase. Then, DXR was intercalated into the DNA, and the physicochemical and biological activities of the DXR/CpG DNA hydrogels were examined. CpG-free X-DNA was also used to prepare DNA complexes to confirm the importance of $\mathrm{CpG}$ motifs with regard to biological and anticancer activity.

\section{Materials and methods \\ 2.1. Chemicals}

RPMI1640 medium, phosphate buffered saline (PBS), and Hanks' balanced salt solution (HBSS) were obtained from Nissui Pharmaceutical (Tokyo, Japan). Fetal bovine serum (FBS) was obtained from MP Biomedicals (Eschwege, Germany). T4 DNA ligase was purchased from Promega (Madison, WI, USA). DNase I was purchased from Takara Bio (Otsu, Japan). Doxorubicin hydrochloride was obtained from Wako Pure Chemical (Osaka, Japan). Transwell plates, $12 \mathrm{~mm}$ in diameter with a pore size of $0.4 \mu \mathrm{m}$, were purchased from Corning Costar (Tokyo, Japan). All other chemicals were of the highest grade available and used without further purification.

\subsection{Cell cultures}

The murine macrophage-like cell line RAW264.7 was obtained from the American Type Culture Collection (Rockville, MD, USA). Murine adenocarcinoma colon26 that stably expresses firefly luciferase gene was prepared as reported previously [9]. Cells were grown in 
RPMI1640 medium supplemented with $10 \%$ heat-inactivated FBS, $0.15 \% \mathrm{NaHCO}_{3}, 100$ units/ml penicillin, $100 \mu \mathrm{g} / \mathrm{ml}$ streptomycin, and 2 $\mathrm{mM}$ L-glutamine at $37{ }^{\circ} \mathrm{C}$ in humidified air containing $5 \% \mathrm{CO}_{2}$. DC2.4, a murine dendritic cell line, kindly donated by Dr. Kenneth Rock (Department of Pathology, University of Massachusetts Medical School, MA, USA) was grown in RPMI1640 medium supplemented with $10 \%$ heat-inactivated FBS, $0.15 \% \mathrm{NaHCO}_{3}, 100$ units/ml penicillin, $100 \mu \mathrm{g} / \mathrm{ml}$ streptomycin, $2 \mathrm{mM}$ L-glutamine, $1 \mu \mathrm{M}$ non-essential amino acids and $1 \mathrm{nM}$ 2-mercaptoethanol.

2.3. Animals

Male ICR mice (4-week-old) and male BALB/c mice (6-week-old) were purchased from Japan SLC, Inc. (Hamamatsu, Japan). Animals were maintained under conventional housing conditions and all animal experiments were approved by the Animal Experimentation Committee of the Graduate School of Pharmaceutical Sciences, Kyoto University.

2.4. $O D N$

All phosphodiester ODNs, including one labeled with fluorescein isothiocyanate (FITC) at the 5'-end, were purchased from Integrated DNA Technologies, Inc. (Coralville, IA, USA). Table 1 summarizes the sequences of the ODNs used in this study. Two different sets of four ODNs were designed as the components for CpG X-DNA and CpG-free X-DNA, respectively, based on the G/C content, free energy and secondary structure as reported previously [18]. The CpG X-DNA possesses 24 CG dinucleotides, including 6 highly immunostimulatory motifs, and has no suppressive CpG motifs, whereas the CpG-free X-DNA contains 10 CG dinucleotides, including no highly immunostimulatory motifs and 9 suppressive (CCG or CGG) CpG motifs [19].

\subsection{Preparation of $X-D N A$}

X-DNA with 4 base overhangs at all the 5 '-ends of a palindromic sequence ACGT was prepared as reported previously [16]. In brief, four ODNs dissolved in an annealing buffer (10 mM Tris, pH 8.0,1 mM ethylenediaminetetraacetic acid (EDTA), and $50 \mathrm{mM} \mathrm{NaCl})$ were mixed together in sterile Milli-Q water at a final concentration of $0.5 \mathrm{mM}$ for each ODN. Mixtures were incubated at $95{ }^{\circ} \mathrm{C}$ for $5 \mathrm{~min}, 65^{\circ} \mathrm{C}$ for $2 \mathrm{~min}$, $62{ }^{\circ} \mathrm{C}$ for $1 \mathrm{~min}$, then slowly cooled to $4{ }^{\circ} \mathrm{C}$. Formation of X-DNA was confirmed by $3 \%$ agarose gel electrophoresis at $100 \mathrm{~V}$ for $45 \mathrm{~min}$. 2.6. Preparation of DNA hydrogels

To construct DNA hydrogels, $1 \mu \mathrm{mol}$ X-DNA underwent random ligation using 0.75 units of T4 DNA ligase (Promega, WI, USA). DNA hydrogels were prepared at different initial concentrations of DNA $(0.1,0.2$ and $0.4 \mathrm{mM})$. The reaction was carried out at room temperature overnight as reported previously [16].

\subsection{Preparation of $D X R / D N A$ complexes}

DXR in Milli-Q water was added to the solution of X-DNA. After $1 \mathrm{~h}$ incubation at room temperature, the mixture was used as a DXR/X-DNA complex without removal of free DXR, because the intercalation of DXR is an equilibrium process [20]. The mixing ratio of DXR and X-DNA was fixed at a 1:10 weight ratio, based on the results of preliminary experiments. Then, DXR/X-DNA was ligated using T4 DNA ligase as described above.

2.8. Observation of the inner structure of DNA hydrogels by scanning electron microscopy

To observe the inner structure of the DNA hydrogels, they were fixed with $2 \%$ glutaraldehyde at room temperature overnight, dehydrated with increasing concentrations of ethanol which was replaced with butyl alcohol, and freeze-dried. The dried material was cracked with a knife and the inner structure of the DNA hydrogels was observed using a field-emission scanning electron microscope (FE-SEM: S4700, HITACHI, Japan).

\subsection{TNF- $\alpha$ release from RAW264.7 cells}

RAW264.7 cells were plated on 24 -well culture plates at a density of $5 \times 10^{5}$ cells $/ \mathrm{ml}\left(2.5 \times 10^{5}\right.$ cells/well $)$ and cultured for $24 \mathrm{~h}$ before use. X-DNA or its components were diluted in RPMI ( $5 \mu \mathrm{g}$ DNA/ml), and added to the cells. In separate experiments, X-DNA or DNA hydrogels diluted in RPMI were added to the cells at different concentrations. Cells were incubated for $8 \mathrm{~h}$, and the supernatants were collected and stored at $-80{ }^{\circ} \mathrm{C}$ until assayed. The level of TNF- $\alpha$ in the supernatant was determined by enzyme-linked immunosorbent assay (ELISA) using an OptEIA $^{\mathrm{TM}}$ set (Pharmingen, San Diego, CA, USA).

2.10. Cellular uptake of DNA by RAW264.7 cells

FITC-labeled ODN was used for the preparation of FITC-labeled single stranded (ss)-, double stranded (ds)- and X-DNA. RAW264.7 cells were plated on 96 -well culture plates at a density of $5 \times 10^{5}$ cells $/ \mathrm{ml}\left(5 \times 10^{4}\right.$ cells/well $)$ and cultured for 24 h. Cells were then washed twice with $100 \mu \mathrm{l}$ PBS, incubated with FITC-DNA for $1 \mathrm{~h}$ at $37^{\circ} \mathrm{C}$ or $4{ }^{\circ} \mathrm{C}$, harvested, and washed twice with $100 \mu \mathrm{PBS}$. Then, the fluorescent intensity of the cells was determined by flow cytometry (FACSCalibur; BD Biosciences, San Jose, CA, USA) using CellQuest software (version 3.1; BD Biosciences).

2.11. Morphological changes in DC2.4 cells

DC2.4 cells were plated on 12-well culture plates at a density of $1 \times 10^{5}$ cells $/ \mathrm{ml}\left(1 \times 10^{5}\right.$ cells/well) and cultured for $24 \mathrm{~h}$. Cells were washed with $1 \mathrm{ml}$ PBS before use. DNA hydrogels $(50 \mu \mathrm{g} / \mathrm{ml}$ ) or lipopolysaccharide (LPS; $100 \mu \mathrm{g} / \mathrm{ml}$ ) in RPMI was added to the cells. After an $8 \mathrm{~h}$-incubation, the cells were fixed with glutaraldehyde at room temperature for $1 \mathrm{~h}$, dehydrated, replaced with butyl alcohol, and freeze-dried. The morphology of the cells was observed using FE-SEM.

2.12. Proliferation of tumor cells co-cultured with RAW264.7 cells

RAW264.7cells $\left(1 \times 10^{5}\right.$ cells $\left./ \mathrm{ml}\right)$ and colon26/Luc cells $\left(5 \times 10^{4}\right.$ cells $\left./ \mathrm{ml}\right)$ were placed in the upper and lower chambers of Transwell plates, respectively. X-DNA, DXR or their mixture was added to the upper side at a final concentration of $10 \mu \mathrm{g} \mathrm{DNA} / \mathrm{ml}$ and $1 \mu \mathrm{g} \mathrm{DXR} / \mathrm{ml}$, and cells were incubated at $37^{\circ} \mathrm{C}$ for $48 \mathrm{~h}$. Then, colon26/Luc cells in the lower chambers were lysed in $1 \mathrm{ml}$ of cell lysis buffer $(0.1 \mathrm{M}$ Tris, $0.05 \%$ Triton-X-100, 2 mM EDTA, pH 7.8). A portion of the buffer was mixed with a luciferase assay buffer (Piccagene, Toyo Ink, Tokyo, Japan), and the chemiluminescence produced was measured in a luminometer (Lumat LB9507, EG and G Berthold, Bad Wildbad, Germany). The luciferase activity was converted to the number of tumor cells as reported previously [21].

2.13. Measurement of gel fraction

To estimate the gel fraction of DNA hydrogels, i.e., the percentage of X-DNA being ligated to other X-DNA, DNA hydrogels were incubated in Milli-Q water at $60{ }^{\circ} \mathrm{C}$ for $24 \mathrm{~h}$, and the amount of DNA in the supernatant was measured as free, non-linked X-DNA using a 
spectrophotometer (UV-1600, Shimadzu, Japan)

2.14. Measurement of DNA-bound fraction of DXR

DXR/DNA hydrogels were incubated in Milli-Q water at $60{ }^{\circ} \mathrm{C}$ for $24 \mathrm{~h}$. The concentrations of DNA and DXR in the supernatant were estimated by measuring the absorbance of DNA and fluorescence of DXR, respectively, in a spectrophotometer (UV-1600) and in a multilabel counter (ARVO ${ }^{\mathrm{TM}}$ MX 1420, Wallac, Finland) with excitation and emission wavelengths of 485 and $560 \mathrm{~nm}$, respectively. The concentration of DXR in the supernatant was used to estimate the fraction of DXR bound to DNA hydrogels.

2.15. Stability of DNA hydrogels and DXR release from DXR/DNA hydrogels in serum

After incubation of DNA hydrogels at $60{ }^{\circ} \mathrm{C}$ for $24 \mathrm{~h}$ to remove non-linked X-DNA, DNA hydrogels with or without DXR were incubated in $100 \mu \mathrm{l}$ mouse serum at $37^{\circ} \mathrm{C}$. The supernatant was collected, centrifuged at $2000 \times \mathrm{g}$ for $5 \mathrm{sec}$, and the concentrations of DNA and DXR were measured as described above. The degradation rate of hydrogels and the release rate of DXR were estimated from the concentrations of DNA and DXR in the supernatant.

2.16. Antitumor activity of DXR/DNA hydrogels in tumor-bearing mice

Colon26/Luc cells $\left(1 \times 10^{6}\right.$ cells/mouse) were inoculated into BALB/c mice. Then, the mice received intratumoral injections of $5 \%$ dextrose, DXR ( $5 \mu \mathrm{g} / \mathrm{mouse}$ ), DNA hydrogels ( $50 \mu \mathrm{g} / \mathrm{mouse}$ ), or DXR/DNA hydrogels ( $5 \mu \mathrm{g}$ DXR and $50 \mu \mathrm{g}$ DNA/mouse) on days 9 and 16 after tumor inoculation. The tumor size was measured periodically with calipers.

2.17. Statistical analysis

Differences were statistically evaluated by one-way analysis of variance (ANOVA) followed by the Fisher's PLSD test for multiple comparisons and by Student's t-test for two groups. A $P$-value of less than 0.05 was considered to be statistically significant.

\section{Results}

\subsection{Formation of $X-D N A$}

The four ODNs used to prepare X-DNA were named Xa, Xb, Xc, and Xd, respectively. Fig. 1A shows the agarose gel electrophoresis of $\mathrm{Xa}$ and mixtures of $\mathrm{Xa}$ and $\mathrm{Xb}, \mathrm{Xa}, \mathrm{Xb}$ and $\mathrm{Xc}$, and all four ODNs after annealing. The migration distance became shorter as the number of ODNs added to the preparations increased. These results suggest that the ODNs added are hybridized to form double stranded DNA, even though almost half of the sequence of each ODN is complimentary to the other ODNs. There was one major band in the lane of all four ODNs, suggesting that X-DNA is efficiently obtained as previously reported [16]. No significant differences were observed between CpG X-DNA and CpG-free X-DNA. Fig. 1B shows the putative structure of CpG X-DNA.

\section{2. $T N F-\alpha$ release from $R A W 264.7$ cells by $X-D N A$}

To investigate the effect of the X-shape formation on the cytokine production by CpG DNA, a variety of components of CpG X-DNA were added to RAW264.7 cells. Fig. 2A shows the concentration of TNF- $\alpha$ in the supernatant of cells $8 \mathrm{~h}$ after addition of $5 \mu \mathrm{g} / \mathrm{ml} \mathrm{DNA}$. Because the sequences and the numbers of the $\mathrm{CpG}$ motif were different among the ODNs used, the numbers of CpG motifs added to cells were not identical even though the same amount $(5 \mu \mathrm{g} / \mathrm{ml})$ of DNA was added. $\mathrm{Xa}, \mathrm{Xb}, \mathrm{Xc}$ and $\mathrm{Xd}$ contained 3, 0, 3 and 0 potent $\mathrm{CpG}$ motifs, respectively, so that the frequency of $\mathrm{CpG}$ motifs in the preparation was calculated to be 1, 0.5, 0.67 and 0.5 for one (Xa), two $(\mathrm{Xa}$ and $\mathrm{Xb})$, and three ODNs (Xa, $\mathrm{Xb}$ and $\mathrm{Xc}$ ), and $\mathrm{X}-\mathrm{DNA}$, respectively. All preparations induced significant production of TNF- $\alpha$, with the highest for $\mathrm{CpG}$ X-DNA. The level of TNF- $\alpha$ induced by CpG X-DNA was significantly greater than that produced by other preparations. Much less TNF- $\alpha$ production was detected when CpG-free X-DNA or its components was added to RAW264.7 cells.

\subsection{Cellular uptake of DNA by RAW264.7 cells}

To investigate whether the increased immunostimulatory activity of CpG DNA by X-shape formation is mediated by increased cellular uptake, the uptake of DNA was examined in RAW264.7 cells using FITC-labeled DNA. Fig. 2B shows the mean fluorescence intensity (MFI) of ss-, ds- and X-DNA. The MFI of cells with added FITC-X-DNA was significantly $(P<0.05)$ greater than that with added FITC-ssDNA or FITC-dsDNA, suggesting that increased cellular uptake is at least partly involved in the X-shape formation-mediated increase in the immunostimulatory ability.

\subsection{Formation of DNA hydrogels}

X-DNA samples were ligated to each other through the adhesive ends to obtain DNA hydrogels. Fig. 3 shows typical FE-SEM images of the inner structure of DNA hydrogels. The images (A, low magnification and B, high magnification) indicated that the gel has a highly ordered structure with plenty of space in the gel, and the diameter ranged from about 200 to 1,000 nm. CpG X-DNA was used to obtain DNA hydrogels containing the $\mathrm{CpG}$ motif (CpG DNA hydrogels). CpG DNA hydrogels were prepared at different concentrations of CpG X-DNA. A higher DNA concentration resulted in a high gel fraction: $44.9 \pm 7.5,60.5 \pm 1.5$ and $72.9 \pm 2.4 \%$ gel fractions for the initial concentrations of $0.1,0.2$ and $0.4 \mathrm{mM}$, respectively.

\subsection{TNF- $\alpha$ release from RAW264.7 cells by DNA hydrogel}

To estimate the effect of gel formation on cytokine release, CpG X-DNA and CpG DNA hydrogels were added to RAW264.7 cells. In general, CpG DNA hydrogels induced higher levels of TNF- $\alpha$ than CpG X-DNA; those prepared at an initial concentration of 0.2 or $0.4 \mathrm{mM}$ induced a significantly $(\mathrm{P}<0.05)$ higher level of TNF- $\alpha$ than CpG X-DNA (Fig. 4A).

3.6. Morphological changes in DC2.4 cells by DNA hydrogels

To investigate whether DNA hydrogels induce maturation of dendritic cells, morphological changes in DC2.4 cells, an immature DC cell line, were evaluated (Fig. 4B-E). The round shape of DC2.4 cells was changed very little following an 8 h-incubation in culture media (Fig. 4B). Addition of LPS, a typical ligand to induce maturation of dendritic cells, markedly changed the shape of the cells to a dendritic form (Fig. 4C), indicating that the cells were matured by the stimulus. The addition of CpG DNA hydrogels also induced similar changes (Fig. 4D), whereas CpG-free DNA hydrogels exhibited hardly any changes (Fig. 4E).

3.7. Antiproliferative activity of DXR/X-DNA on tumor cells cocultured with RAW264.7 cells

Antiproliferative activity was evaluated by measuring the luciferase activity of colon26/Luc cells cocultured with RAW264.7 cells in Transwell systems. When added to RAW264.7 cells, CpG X-DNA or DXR significantly reduced the number of colon26/Luc cells (Fig. 5). 
CpG-free X-DNA had no significant effect on the number of colon26/Luc cells. The number of colon26/Luc cells treated with DXR/CpG X-DNA was significantly smaller than those treated with DXR alone or DXR/CpG-free X-DNA, indicating that DXR and CPG X-DNA have at least additive effects on inhibition of the proliferation of colon26/Luc cells.

3.8. Degradation and DXR release from DXR/DNA hydrogels in serum

The gel fraction of DXR/DNA hydrogels $(82.7 \pm 5.8 \%)$ was higher than that of DNA hydrogels $(71.2 \pm 2.5 \%)$. About $78 \%$ of added

DXR was found to be bound to DNA hydrogels. The fraction was reduced by incubation of the gels in mouse serum, and the rate was slower for DXR/DNA hydrogels than for those without DXR (Fig. 6A). DXR was gradually released from DXR/DNA hydrogels at a speed comparable with the gel degradation (Fig. 6B).

3.9. Inhibition of colon $26 /$ Luc subcutaneous tumor growth by DXR/DNA hydrogels

The growth of a colon26/Luc subcutaneous tumor was monitored after intratumoral injections of DXR, DNA hydrogels or DXR/DNA hydrogels. Fig. 7 shows the growth of tumor tissues in mice. Injections of CpG-free DNA hydrogels had no significant effects on tumor growth, whereas CpG DNA hydrogels had some effect. Injections of DXR were also effective for the first 4 weeks but, thereafter, the tumor started to increase in size. DXR/CpG-free DNA hydrogels, which could slowly release DXR, were also effective and DXR/CpG DNA hydrogels showed the best results.

\section{Discussion}

Hydrogels are one of the best systems for sustained or controlled drug delivery, and a variety of natural or synthetic compounds have been used for the preparation of hydrogels with diverse characteristics [17]. An important property of such drug delivery systems is biodegradability. DNA hydrogels [16] can be completely made from natural materials, i.e., DNA, so there should be little concern about safety and accumulation issues. The gel strength can be controlled by the shape of the DNA units, and X-DNA was found to be good for obtaining rigid hydrogels compared with Y- or T-DNA [16]. In the present study, we found that the addition of DXR to DNA hydrogels increased the gel fraction and reduced the gel degradation rate (Fig. 6). DXR intercalates between adjacent DNA base pairs, and interferes with DNA strand separation. These properties of DXR explain why the DXR/DNA hydrogels had a higher gel fraction compared with DNA hydrogels without DXR. Sustained delivery of anticancer agents, such as DXR, has been examined as an efficient and safe treatment for cancer [22]. The DNA hydrogels prepared were found to possess properties characteristic of hydrogels, including the controlled release of incorporated DXR.

Unlike most hydrogels, DNA hydrogels can be immunologically active when they contain immunostimulatory sequences. DNA containing unmethylated CG dinucleotide has been examined for use in cancer immunotherapy in combination with anticancer agents [23] or antigens [24]. Although phosphorothioate CpG DNA is generally used for this purpose because of resistance to degradation, it has been reported that phosphorothioate DNA induces contact hypersensitivity [25] and toxic shock [26]. Therefore, natural phosphodiester DNA was used in the present study to develop DNA hydrogels, although the incorporation of phosphorothioate DNA was found to increase the immunostimulatory activity of CpG DNA when built into Y-DNA [Matsuoka et al., submitted].

The immunostimulatory activity of CpG DNA is based on the interaction with TLR9, which is expressed in dendritic cells, B cells and other cells [8]. Because the TLR9 is localized in the endosomes, the vesicular compartment within cells, CpG DNA should be internalized via endocytosis to come into contact with the receptor. Although the precise mechanism of cellular uptake of DNA hydrogels needs further study, the results on the maturation of DC2.4 cells clearly showed that CpG DNA hydrogels can activate cells in a manner which is dependent on the presence of CpG motifs (Fig. 4). DNA hydrogels were degraded with time and the components were released into the supernatant when incubated in mouse serum. Thus, DNA hydrogels are degraded into pieces small enough to be taken up by cells via endocytosis. The results of TNF- $\alpha$ release from RAW264.7 cells raise an interesting hypothesis that DNA hydrogels or their degraded materials are more efficient than CpG X-DNA in stimulating TLR9-positive cells (Fig. 4A). These results are in good agreement with other DNA preparations with many branches, such as Y-shape [14], X-shape (Fig. 2A) and dendrimer-like structures [15].

The precise mechanism whereby these branched DNA preparations are more potent than single- or double stranded DNA is presently unknown, but some possibilities can be considered based on previous observations. The uptake of DNA by splenic dendritic cells, B cells and peritoneal macrophages was increased by insertion of a polyG sequence, which resulted in the formation of higher-order structures of DNA [27]. Cross-linking of two DNAs increased the expression of NF- $\mathrm{kB}$ and the production of cytokines [28]. This structure-dependent increase in the activity of DNA could be partly explained by increased interaction of DNA with TLR9, because DNA with a high-order structure efficiently induced TLR9 crosslinking [27]. Furthermore, the high-mobility group box 1 (HMGB1), a CpG DNA-binding protein that shuttles in and out of immune cells and interacts with TLR9 to regulate inflammatory responses, has been reported to bind preferentially to DNA with a high order structure, such as 4-way junction DNA [29]. Therefore, the increased immunostimulatory activity of CpG X-DNA and CpG DNA hydrogels could be probably associated with its stronger binding to HMGB1. Further studies are required to confirm this hypothesis.

The sequence of DNA was new and designed according to the rules and criteria for the immunostimulatory activity of DNA [16,19]. Accordingly, CpG-free X-DNA, which has many CG dinucleotides but no potent CpG motifs, was also prepared. The sequences like CCG and CGG, which are in the CpG-free X-DNA, are known to be neutralizing CpG motifs that block immune activation by CpG DNA. We found that neither CpG-free X-DNA nor CpG-free DNA hydrogels stimulate immune cells (Fig. 2A, 4E), indicating that the DNA hydrogel-induced responses are completely due to the presence of $\mathrm{CpG}$ motifs.

DXR, an anthracycline frequently used in the treatment of breast cancer, was selected as a model drug to be incorporated into X-DNA and DNA hydrogels, because it can be intercalated into DNA [30]. In a previous study [11], we used plasmid DNA to deliver DXR to metastatic tumor tissues. Because tumor tissues are enriched with immune cells, such as dendritic cells and macrophages [31], DNA can be recognized by these cells and induce the release of anticancer cytokines, such as IL-12, from the cells. DXR is considered to be released from these cells and reach adjacent cancer cells, because DXR is chemically stable and has been reported to be released from macrophages in tumor tissues after administration as DXR containing liposomes [32]. Although this assumption needs further confirmation, it is supported by experimental results using a DXR/plasmid DNA complex [11] or DXR/CpG X-DNA (Fig. 5). Addition of DXR/CpG X-DNA to RAW264.7 cells resulted in no significant death of RAW264.7 cells in terms of the cell number measured by MTT assay (data not shown). The higher cytotoxic activity of DXR/CpG X-DNA compared with DXR/CpG-free X-DNA demonstrated that CpG motif-mediated production of soluble factors, probably 
antitumor cytokines, is effective in inhibiting the proliferation of colon26/Luc cells. Similar results were obtained after intratumoral injections of DXR/DNA hydrogels to tumor-bearing mice (Fig. 7). In this model, DXR and CpG DNA showed at least additive effects on tumor growth.

\section{Conclusion}

The present study demonstrates that DNA hydrogels are effective drug delivery systems that achieve sustained delivery of not only anticancer agents but also immunostimulatory signals. These findings will open up a wide range of applications of DNA, a natural, biodegradable, and immunostimulatory compound, for use in sustained drug delivery systems for a variety of anticancer agents and antigens for cancer immunotherapy.

\section{Acknowledgements}

This work was supported in part by Health Labour Sciences Research Grants for Research on Advanced Medical Technology from the Ministry of Health Labour and Welfare of Japan. We would like to thank Mr. Mako Fujioka, Ms. Keiko Furuta and Mr. Yasuharu Kouda (Laboratory for Electron Microscopy, Center for Anatomical Studies, Graduate School of Medicine, Kyoto University) for their technical assistance in FE-SEM observations.

\section{References}

[1] Weiner GJ. The immunobiology and clinical potential of immunostimulatory CpG oligodeoxynucleotides. J Leukoc Biol 2000;68:455-463.

[2] Bremers AJ, Parmiani G. Immunology and immunotherapy of human cancer: present concepts and clinical developments. Crit Rev Oncol Hematol 2000;34:1-25.

[3] Berzofsky JA, Ahlers JD, Belyakov IM. Strategies for designing and optimizing new generation vaccines. Nat Rev Immunol 2001;1:209-219.

[4] Klinman DM. Immunotherapeutic uses of CpG oligodeoxynucleotides. Nat Rev Immunol 2004;4:249-258.

[5] Krieg AM. CpG motifs in bacterial DNA and their immune effects. Annu Rev Immunol 2002;20:709-760.

[6] Klinman DM, Yi AK, Beaucage SL, Conover J, Krieg AM. CpG motifs present in bacteria DNA rapidly induce lymphocytes to secrete interleukin 6, interleukin 12, and interferon $\gamma$. Proc Natl Acad Sci USA 1996;93:2879-2883.

[7] Sparwasser T, Miethke T, Lipford G, Erdmann A, Häcker H, Heeg K, et al. Macrophages sense pathogens via DNA motifs: induction of tumor necrosis factor- $\alpha$-mediated shock. Eur J Immunol 1997;27:1671-1679.

[8] Kumagai Y, Takeuchi O, Akira S. TLR9 as a key receptor for the recognition of DNA. Adv Drug Deliv Rev 2008;60:795-804.

[9] Kuramoto Y, Nishikawa M, Hyoudou K, Yamashita F, Hashida M. Inhibition of peritoneal dissemination of tumor cells by single dosing of phosphodiester CpG oligonucleotide/cationic liposome complex. J Control Release 2006;115:226-233.

[10] Krieg AM. Toll-like receptor 9 (TLR9) agonists in the treatment of cancer. Oncogene 2008;27:161-167.

[11] Mizuno Y, Naoi T, Nishikawa M, Rattanakiat S, Hamaguchi N, Hashida M, et al. Simultaneous delivery of doxorubicin and immunostimulatory CpG motif to tumors using a plasmid DNA/doxorubicin complex in mice. J Control Release 2010;141:252-259.

[12] Li Y, Tseng YD, Kwon SY, D'Espaux L, Bunch JS, McEuen PL, et al. Controlled assembly of dendrimer-like DNA. Nat Mater 2004;3:38-42.

[13] Nishikawa M, Rattanakiat S, Takakura Y. DNA-based nano-sized systems for pharmaceutical and biomedical applications. Adv Drug Deliv Rev 2010;62:626-632.

[14] Nishikawa M, Matono M, Rattanakiat S, Matsuoka N, Takakura Y. Enhanced immunostimulatory activity of oligodeoxynucleotides by Y-shape formation. Immunology 2008;124:247-255.

[15] Rattanakiat S, Nishikawa M, Funabashi H, Luo D, Takakura Y. The assembly of a short linear natural cytosine-phosphate-guanine DNA into dendritic structures and its effect on immunostimulatory activity. Biomaterials 2009;30:5701-5706.

[16] Um SH, Lee JB, Park N, Kwon SY, Umbach CC, Luo D. Enzyme-catalysed assembly of DNA hydrogel. Nat Mater 2006;5:797-801.

[17] Hoffman AS. Hydrogels for biomedical applications. Adv Drug Deliv Rev 2002;54:3-12.

[18] Um SH, Lee JB, Kwon SY, Li Y, Luo D. Dendrimer-like DNA-based fluorescence nanobarcodes. Nat Protoc 2006;1:995-1000.

[19] Lenert P, Goeken AJ, Ashman RF. Extended sequence preferences for oligodeoxyribonucleotide activity. Immunology 2006;117:474-481.

[20] Phillips DR, Greif PC, Boston RC. Daunomycin-DNA dissociation kinetics. Mol Pharmacol 1988;33:225-230.

[21] Hyoudou K, Nishikawa M, Umeyama Y, Kobayashi Y, Yamashita F, Hashida M. Inhibition of metastatic tumor growth in mouse lung by repeated administration of polyethylene glycol-conjugated catalase: quantitative analysis with firefly luciferase-expressing melanoma cells. Clin Cancer Res 2004;10:7685-7691.

[22] Chun C, Lee SM, Kim CW, Hong KY, Kim SY, Yang HK, et al. Doxorubicin-polyphosphazene conjugate hydrogels for locally controlled delivery of cancer therapeutics. Biomaterials 2009;30:4752-4762.

[23] Manegold C, Gravenor D, Woytowitz D, Mezger J, Hirsh V, Albert G, et al. Randomized phase II trial of a toll-like receptor 9 agonist oligodeoxynucleotide, PF-3512676, in combination with first-line taxane plus platinum chemotherapy for advanced-stage non-small-cell lung cancer. J Clin Oncol 2008;26:3979-3986.

[24] Krishnamachari Y, Salem AK. Innovative strategies for co-delivering antigens and CpG oligonucleotides. Adv Drug Deliv Rev 2009;61:205-217.

[25] Akiba H, Satoh M, Iwatsuki K, Kaiserlian D, Nicolas JF, Kaneko F. CpG immunostimulatory sequences enhance contact hypersensitivity responses in mice. J Invest Dermatol 2004;123:488-493.

[26] Heikenwalder M, Polymenidou M, Junt T, Sigurdson C, Wagner H, Akira S, et al. Lymphoid follicle destruction and immunosuppression after repeated CpG oligodeoxynucleotide administration. Nat Med 2004;10:187-192.

[27] Krieg AM. Therapeutic potential of Toll-like receptor 9 activation. Nat Rev Drug Discov 2006;5:471-484. 
[28] Yu D, Kandimalla ER, Bhagat L, Tang JY, Cong Y, Tang J, et al. 'Immunomers'--novel 3'-3'-linked CpG oligodeoxyribonucleotides as potent immunomodulatory agents. Nucleic Acids Res 2002;30:4460-4469.

[29] Ivanov S, Dragoi AM, Wang X, Dallacosta C, Louten J, Musco G, et al. A novel role for HMGB1 in TLR9-mediated inflammatory responses to CpG-DNA. Blood 2008;110:1970-1981.

[30] Judson IR. Anthrapyrazoles: true successors to the anthracyclines? Anticancer Drugs 1991;2:223-231.

[31] Talmadge JE, Donkor M, Scholar E. Inflammatory cell infiltration of tumors: Jekyll or Hyde. Cancer Metastasis Rev 2007;26:373-400.

[32] Storm G, Steerenberg PA, Emmen F, van Borssum Waalkes M, Crommelin DJ. Release of doxorubicin from peritoneal macrophages exposed in vivo to doxorubicin-containing liposomes. Biochim Biophys Acta 1988;965:136-145.

Table 1 The sequences of ODNs used for the preparation of X-DNA.

\begin{tabular}{|c|c|}
\hline ODN & Sequence \\
\hline CpG Xa & acgt tcgctgacgttgcagaca tcacgttgacgctgtcga \\
\hline $\mathrm{CpG} \mathrm{Xb}$ & acgt tcgacagcgtcaacgtga aacgtgaagcgtctgcga \\
\hline $\mathrm{CpG} \mathrm{Xc}$ & acgt tcgcagacgcttcacgtt gcagacagacgttgacga \\
\hline CpG Xd & acgt tcgtcaacgtctgtctgc tgtctgcaacgtcagcga \\
\hline CpG-free Xa & agct aggcaccgtagtcaatcg ccgatgtgtccaaagcct \\
\hline CpG-free $\mathrm{Xb}$ & agct aggctttggacacatcgg tgctcctaccgtactcct \\
\hline CpG-free Xc & agct aggagtacggtaggagca gtttcggcatgtccacct \\
\hline CpG-free Xd & agct aggtggacatgccgaaac cgattgactacggtgcct \\
\hline
\end{tabular}

A

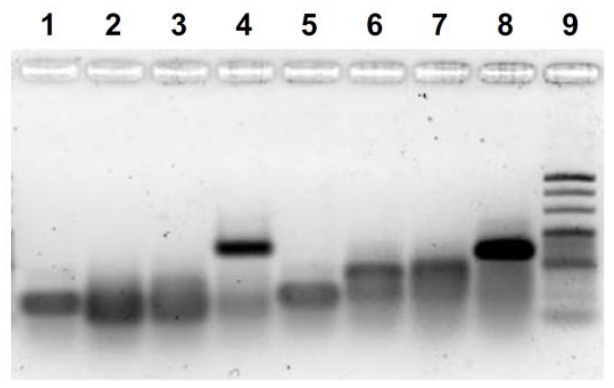

$B$

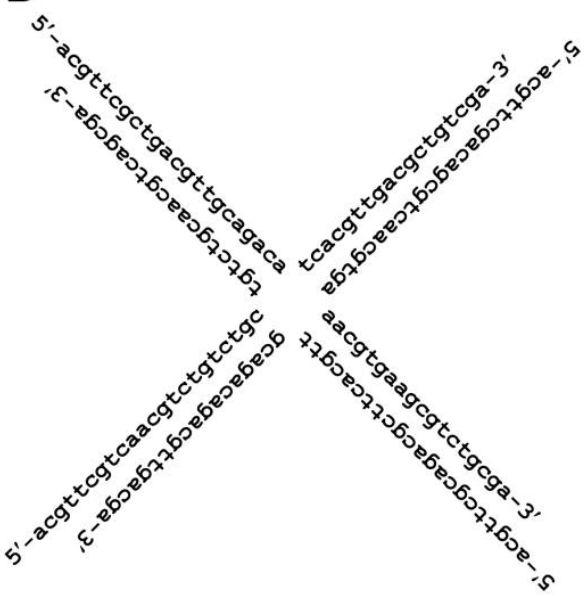

Fig.1. Preparation of X-DNA. A, Agarose gel electrophoresis of CpG X-DNA, CpG-free X-DNA and their components. Samples were run on $3 \%$ agarose gel at $100 \mathrm{~V}$ for $45 \mathrm{~min}$. Lane 1, CpG Xa; lane 2, CpG Xa and CpG Xb; lane 3, CpG Xa, CpG Xb and CpG Xc; lane 4, CpG X-DNA; lane 5, CpG-free Xa; lane 6, CpG-free Xa and CpG-free Xb; lane 7, CpG-free Xa, CpG-free Xb and CpG-free Xc; lane 8, CpG-free X-DNA; lane 9, 20-bp DNA ladder (Takara Bio Inc., Otsu, Japan). B, Putative structure of CpG X-DNA. 

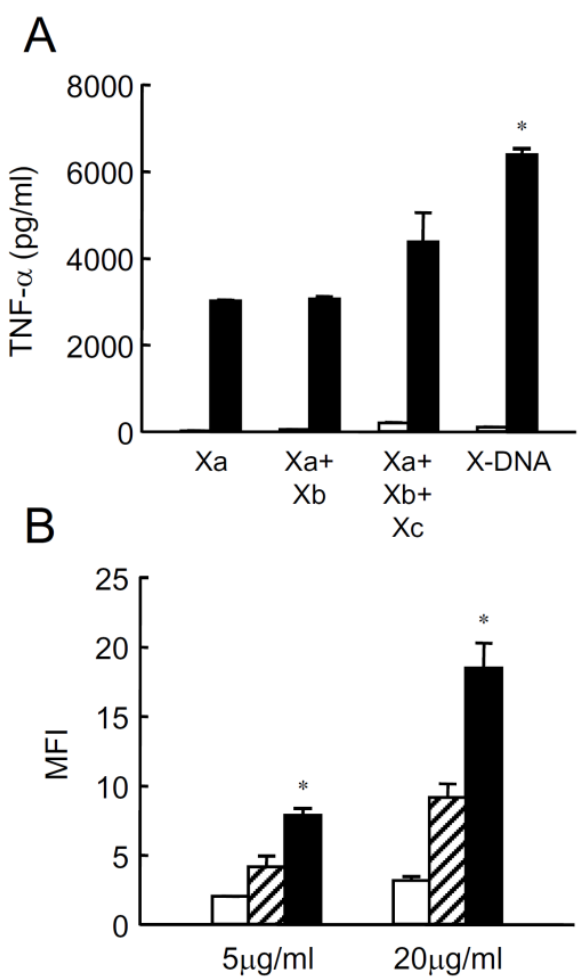

Fig. 2. Interaction of X-DNA with RAW264.7 cells. A, TNF- $\alpha$ release from RAW264.7 cells after addition of CpG-free X-DNA (open bars) or CpG X-DNA (closed bars). TNF- $\alpha$ in the supernatant was measured at $8 \mathrm{~h}$ after addition of each X-DNA at a concentration of $5 \mu \mathrm{g} / \mathrm{ml}$. Results are expressed as mean $\pm S D$ of three determinations. ${ }^{*} P<0.05$, significantly different from any other DNA preparations. $B$, Uptake of ss- (open bars), ds- (hatched bars) and X-DNA (closed bars) in RAW264.7 cells. RAW264.7 cells were incubated with FITC-labeled DNA for $1 \mathrm{~h}$ at indicated concentrations at $37^{\circ} \mathrm{C}$. The amounts of DNA associated with cells were measured by flow cytometry. Results are expressed as the mean \pm SD of three determinations. ${ }^{*} P<0.05$, significantly different from ss- and ds-DNA at the same concentrations.

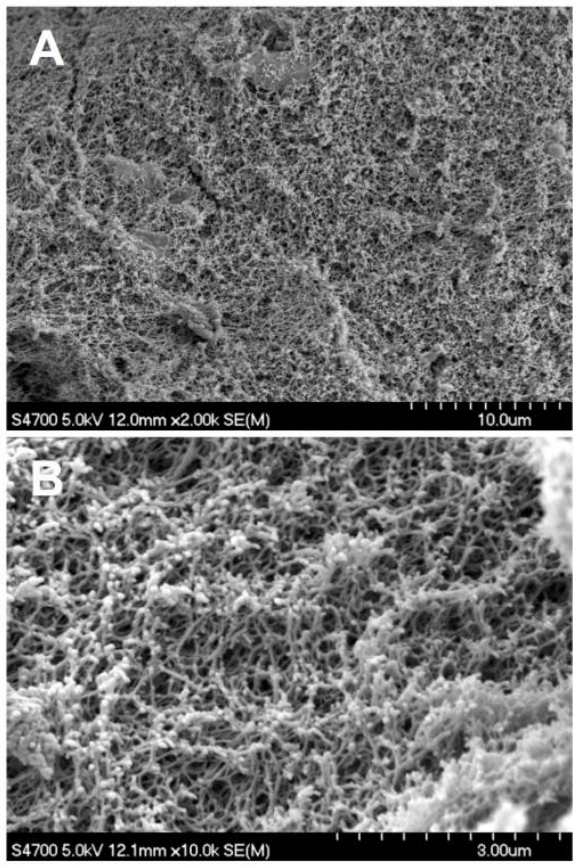

Fig.3. FE-SEM images of the inner structure of DNA hydrogels. Images were taken using a field-emission scanning electron microscope at $(A)$ low and $(B)$ high magnifications. 

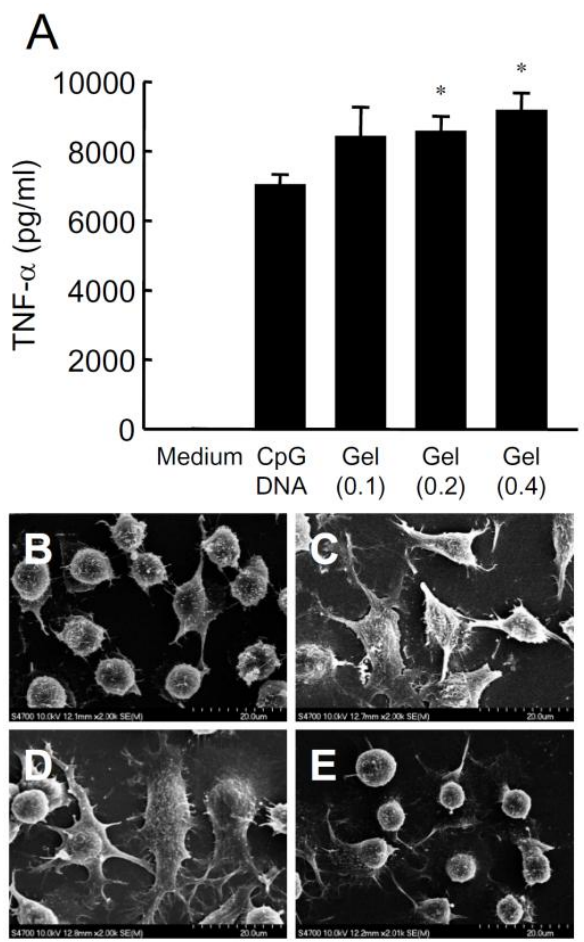

Fig. 4. Activation of immune cells by CpG DNA hydrogels. A, TNF- $\alpha$ release from RAW264.7 cells after addition of CpG X-DNA (CpG DNA) or CpG DNA hydrogels (Gel). The numbers in parentheses indicate the initial concentrations of DNA (mM) for the preparation of CpG DNA hydrogels. TNF- $\alpha$ in the supernatant was measured at $8 \mathrm{~h}$ after addition of each DNA at a concentration of $20 \mu \mathrm{g} / \mathrm{ml}$. Results are expressed as mean \pm SD of three determinations. ${ }^{*} P<0.05$, significantly different from CpG X-DNA (CpG DNA). B-E, SEM images of DC2.4 cells after addition of LPS or DNA hydrogels. DC2.4 cells were incubated in medium containing $(B)$ no hydrogel, $(C)$ LPS $(50 \mu \mathrm{g} / \mathrm{ml}),(D)$ CpG DNA hydrogels $(20 \mu \mathrm{g} / \mathrm{ml})$ or $(E)$ CpG-free DNA hydrogels $(20 \mu \mathrm{g} / \mathrm{ml})$ for $8 \mathrm{~h}$ at $37^{\circ} \mathrm{C}$. The morphology of the cells was observed under FE-SEM.

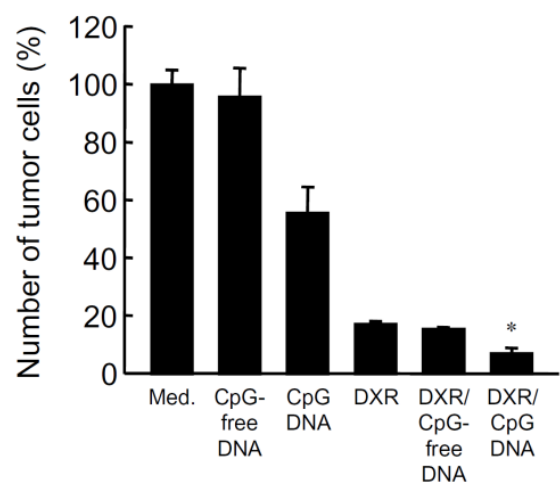

Fig. 5. Antiproliferative activity of DXR/DNA complex against colon26/Luc cells. RAW264.7cells and colon26/Luc cells were placed in the upper and lower chambers of Transwell plates, respectively, and DNA, DXR or their mixture was added to the upper side at a final concentration of $10 \mu \mathrm{g} \mathrm{DNA} / \mathrm{ml}$ and $1 \mu \mathrm{g} \mathrm{DXR} / \mathrm{ml}$. After $48 \mathrm{~h}$, the number of colon26/Luc cells in the lower chambers was estimated by measuring the luciferase activity of the cells. Results are expressed as mean \pm SD of three determinations. ${ }^{*} P<0.05$, significantly different from the other groups. 
A

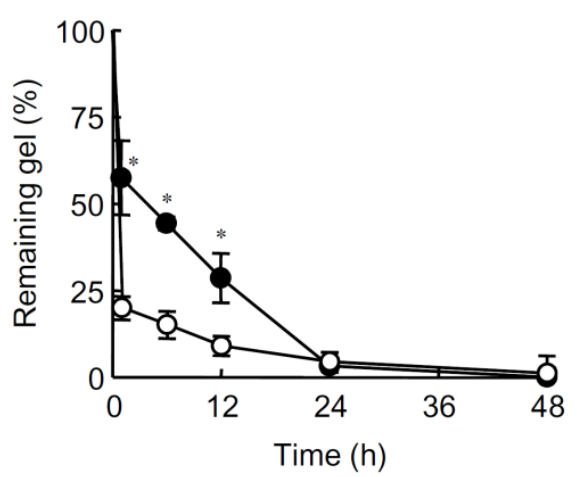

B

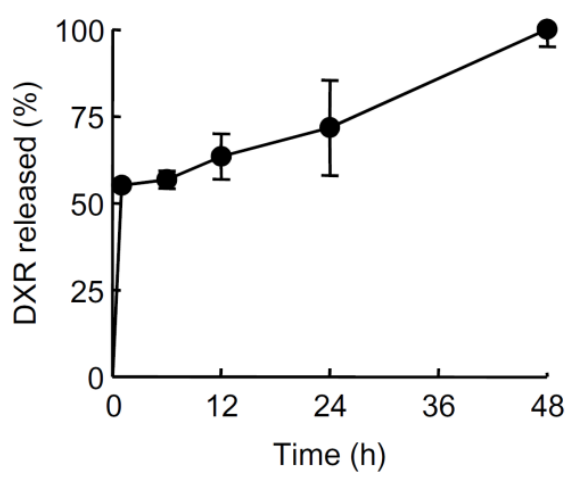

Fig. 6. Degradation and DXR release from DNA hydrogels in mouse serum. A, Degradation of DNA hydrogels with or without DXR. Gels were incubated in mouse serum at $37^{\circ} \mathrm{C}$, and the concentration of DNA in the supernatant was measured. Results are expressed as mean $\pm \mathrm{SD}$ of three determinations. ${ }^{*} P<0.05$, significantly different from $\mathrm{DXR}$-free DNA hydrogels. $B$, DXR release from DXR/DNA hydrogels. Gels were incubated in mouse serum at $37^{\circ} \mathrm{C}$, and the concentration of $\mathrm{DXR}$ in the supernatant was measured. Results are expressed as mean \pm SD of three determinations.

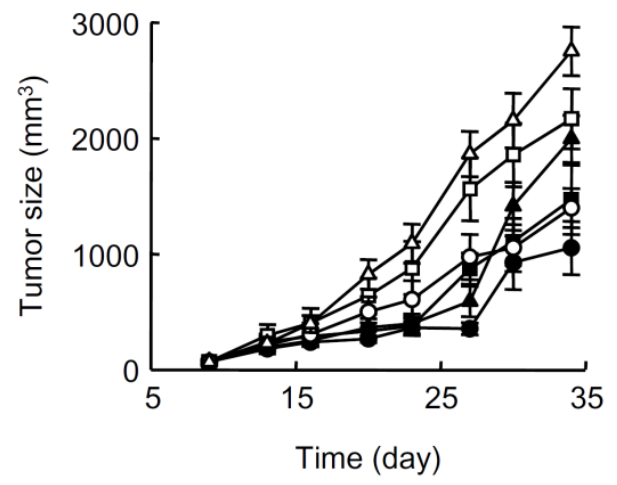

Fig. 7. Effect of DXR, DNA hydrogels or their complexes on the growth of colon26/Luc tumor in mice. Tumor-bearing mice received two intratumoral injections on days 9 and 16 after tumor inoculation. The tumor size was measured with calipers periodically.

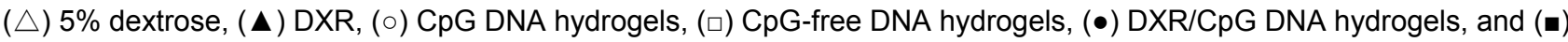
$\mathrm{DXR} / \mathrm{CpG}$-free DNA hydrogels. Results are expressed as mean $\pm \mathrm{SD}$ of four mice. 